Brit. J. industr. Med., 1952, 9, 180.

\title{
THE CAUSES OF DEATH AMONG GAS-WORKERS WITH SPECIAL REFERENCE TO CANCER OF THE LUNG
}

\author{
BY \\ RICHARD DOLL \\ From the Statistical Research Unit, Medical Research Council, London
}

(RECEIVED FOR PUBLICATION MARCH 13, 1952)

Gas-workers are known to be specially liable to develop cancer of the skin and bladder (Henry, Kennaway, and Kennaway, 1931) and it has been suggested that they also suffer an unduly high mortality from cancer of the lung (Kennaway and Kennaway, 1947). The latter suggestion is based on an analysis of male deaths certified as being due to cancer of the lung in England and Wales during the period 1921-38. Fifty-six occupations were studied, including seven groups of gas-workers. The number of deaths attributed to cancer of the lung was greater, in each of the seven groups, than the number expected from the experience of the total and the excess varied from $29 \%$ to as much as $184 \%$. Such evidence is strongly suggestive of a special occupational risk. It is not conclusive, because the numbers of men engaged in the various occupations had to be deduced from the evidence provided by the censuses of 1921 and 1931 and were not known with any certainty after the latter date. Further evidence has, therefore, been sought.

\section{Method of Investigation}

The method of study adopted was a comparison between the mortality rates experienced by male pensioners of a large London gas company and the male population of Greater London. The pension scheme covered all employees of the company, other than salaried staff, who had reached the age of 55 at the time of retirement ; in addition, 11 men, alive during the period of the study, had retired under the age of 55 and had been given pensions at the company's discretion. A small proportion of those who retired before 1930 had voluntarily relinquished their membership of the scheme, but the scheme was otherwise all-embracing. The usual age for retirement was 65 ; an appreciable proportion of those who retired earlier must be assumed to have done so for health reasons, particularly when the age of retirement was under 60 . The study was, therefore, confined to pensioners over 60 , but men who had retired earlier were included on reaching 60 , so as not to bias the investigation by the exclusion of a particularly unhealthy group. Men who were in receipt of a pension on January 1, 1939, or who began to receive a pension in the succeeding 10 years were studied. The date of birth, the date of entering the pension scheme and, where applicable, the date and cause of death, were recorded for each pensioner, and the number in each five-year age group was counted separately for each of the years 1939 to 1948. A pensioner who was in receipt of a pension before the beginning of a year and who was alive at the end of the year was counted as one unit; a pensioner who received a pension before the beginning of the year but who died during it, and one who began to receive a pension during the year and who survived to the end of it, were each counted as half a unit ; one who began to receive a pension and who died during the same year was counted as a quarter of a unit.

The causes of death recorded by the company had been copied from death certificates and could, therefore, be classified directly in selected categories according to the Registrar General's rules for classification. Where doubt existed about the correct classification, the case was referred to the General Register Office and the particular classification under which the death had been put at the time of death was determined.

The number of deaths expected to have occurred from each category of diseases was calculated in the first place from the mortality experience in the same years of the male population of England and Wales. To the number of pensioners alive each 
year, in each five-year age group, the corresponding mortality rate experienced throughout the whole of England and Wales in the same age group was applied. For instance, for all England and Wales the mortality rate from diseases of the cardiovascular system among men aged 65-69 in 1940 was 15.7 per 1,000 . The number of male pensioners of that age, alive that year, was 451 and the number of deaths expected was, therefore, $451 \times 15 \cdot 7 / 1,000$ $=7 \cdot 1$. The total number of deaths expected from each group of diseases was obtained by adding the numbers thus calculated for each age group for each of the 10 years.

The great majority of the pensioners were London residents and, when they died, died in London, so that it would clearly have been preferable to have based the calculations of the expected deaths upon the death rates observed in London rather than upon the rates for all England and Wales, since the rates for England and Wales and for Greater London differ in some respects. Unfortunately the required death rates in Greater London were not available for sufficiently small age groups. It was, however, possible to apply a coarse London weighting, or correcting, factor to the deaths as calculated from the England and Wales rates and thus to bring them, it is believed, more into conformity with the numbers that would be expected for residents in Greater London. Weights could not be calculated for all the disease groups studied because the numbers of deaths are not given by the Registrar General separately for Greater London for all diseases.

Weights were calculated for tuberculosis, cancer and other tumours, diseases of the cardiovascular system, the respiratory system and the digestive system, for violence, and for " all causes" by dividing the mortality rates from each cause among men of 65 and over* in Greater London by the corresponding rates for England and Wales. The necessary figures are provided by the Registrar General in his annual reviews for 1939, 1940, 1941 , and 1948 ; for the years $1942-47$ no estimates of the population by age in Greater London are available. The ratios for each disease group were calculated for each of the four years (two of which were war years and two of which were mainly years of peace) and were averaged to give the weights for the whole period.

The Registrar General does not after 1939 give the number of deaths attributed to senility in Greater London for different age groups. In 1939, however, $99.3 \%$ of the male deaths attributed to senility were in men of 65 or over, so that the total deaths from senility were used for calculating the rates over 65 in the years 1940, 1941, and 1948; very little error can have been

\footnotetext{
* Figures are available for this age group, but not for the more * Figures are available for this
appropriate one of 60 and over.
}

introduced by so doing. The total mortality rates for all causes other than those referred to above were calculated by subtracting the rates for the separate disease groups (including the estimated rates for senility) from the rates for all causes. Weights for the whole period for these two groups, senility and other causes, were then calculated from the mortality rates as above.

Figures for cancer of the stomach by age in Greater London are not available for 1939; the required weighting was, therefore, obtained by duplicating the figure for the only other year of peace available (1948) before averaging.

No figures are available for cancer of the lung by age in Greater London for any of the years 1939-1948. The mortality rate is available for Greater London in 1948 for men of all ages, and it was assumed that the ratio between this and the rate for all men in England and Wales would be a reasonable index of the required ratio for men of 65 and over. There is no reason to suppose that the ratios for this disease were markedly affected by war conditions, and the ratio for 1948 was, therefore, taken as the best estimate of the weighting for lung cancer for the whole period.

The weighting for "other tumours" was obtained from the figures for 1940,1941 , and 1948 by a method similar to that used for cancer of the stomach. The expected numbers of deaths in men of 65 and over were, however, obtained by subtracting the numbers of deaths due to cancer of the stomach and the estimates of the numbers due to cancer of the lung from the totals for all tumours.

Results
The number of pensioners alive each calendar year in each age group is shown in Table 1 . The total number of deaths and the number of deaths observed in each of the disease categories studied are shown in Table 2, together with the corresponding numbers of deaths expected on the basis of the experience of all England and Wales. From this comparison, it would appear that the pensioners suffered an excess mortality from cancer and a decreased mortality from diseases of the central nervous system and from senility. The total mortality from all causes is close to the expected and the small excess is not statistically significant.

When the cancer deaths are subdivided according to site, it is seen that the excess is largely due to an excess of deaths from cancer of the lungs and pleura (25 against 10.4 expected). Most of the other groups show a slight excess but the differences are small and, taken all together, are not significant (131 observed against 113.1 expected; $0.05<\mathrm{P}<$ $0 \cdot 10$ ). The deaths from cancer of the skin and from cancer of the bladder (included in cancer of the urinary organs) are too few for separate assessment.

Comparison between the pensioners who lived and worked and mostly died in London, and the 
TABLE 1

NUMBER OF PENSIONERS ALIVE IN EACH AGE GROUP FROM 1939 TO 1948*

\begin{tabular}{|c|c|c|c|c|c|c|c|c|c|c|c|c|}
\hline \multicolumn{3}{|c|}{ Age } & 1939 & 1940 & 1941 & 1942 & 1943 & 1944 & 1945 & 1946 & 1947 & 1948 \\
\hline $60-64$ & $\cdots$ & . & $63 \frac{1}{4}$ & $64 \frac{1}{2}$ & 63 & 63 & 531 & 45 & 46 & $56 \frac{1}{2}$ & 541 & $52 \frac{1}{2}$ \\
\hline $65-69$ & $\cdots$ & .. & 434 & 451 & 440 & $401 \frac{1}{4}$ & 372 & $350 \frac{1}{2}$ & $345 \frac{1}{2}$ & $384 \frac{3}{4}$ & $430 \neq$ & 4343 \\
\hline $70-74$ & . & . & 320 & $333 \frac{1}{2}$ & $324 \frac{1}{2}$ & 335 & $340 \frac{1}{2}$ & 341 & $357 \frac{1}{2}$ & $361 \frac{1}{2}$ & $360 \frac{1}{2}$ & $351 \frac{1}{2}$ \\
\hline $75-79$ & . & . & $156 \frac{1}{2}$ & $174 \frac{1}{2}$ & $195 \frac{1}{2}$ & 199 & 212 & 220 & $225 \frac{1}{2}$ & $216 \frac{1}{2}$ & $212 \frac{1}{2}$ & 223 \\
\hline $80-84$ & . & . & $57 \frac{1}{2}$ & 52 & $58 \frac{1}{2}$ & $70 \frac{1}{2}$ & 80 & 90 & $98 \frac{1}{2}$ & $112 \frac{1}{2}$ & 113 & $123 \frac{1}{2}$ \\
\hline $85+\ldots$ & . & . & $18 \frac{1}{2}$ & $21 \frac{1}{2}$ & $22 \frac{1}{2}$ & 24 & $20 \frac{1}{2}$ & $21 \frac{1}{2}$ & 21 & $23 \frac{1}{2}$ & 32 & 35 \\
\hline All age & $0+$ & . & 1,0493 & 1,097 & 1,104 & $1,092 \frac{3}{4}$ & $1,078 \frac{1}{4}$ & 1,068 & 1,094 & 1,155 & $1,202 \frac{1}{2}$ & $1,220 \frac{1}{4}$ \\
\hline
\end{tabular}

${ }^{*}$ For explanation of fractions see p. 000 .

general male population of England and Wales is, however, as stated above, probably not justified. It is, for example, believed that cancer of the lung is commoner in London than in most of the country, whereas senility is less frequently resorted to as a cause of death on London death certificates. It is preferable, therefore, to make the comparison with the causes of death in the limited population of Londoners.

The ratios between the mortality rates of men over 65 in Greater London and in all England and Wales have been used, as already described, as weights to enable the expected number of deaths among Londoners to be estimated from the experience of the whole country. The results are shown in Table 3. Information was not available to enable the weights to be calculated for all the disease groups. When it has been possible to calculate a weight the result has been that the estimated numbers of deaths expected among a population of Londoners comparable with the group of pensioners are close to the actual numbers observed for all categories of disease other than for cancer of the lung. For lung cancer, the observed mortality is almost double the expected and the excess is statistically highly significant. In no other group is the difference between the observed and expected deaths such that it cannot reasonably

TABLE 2

CAUSES OF DEATH OF PENSIONERS FROM 1939 TO 1948 COMPARED WITH THE EXPERIENCE OF ALL ENGLAND AND WALES

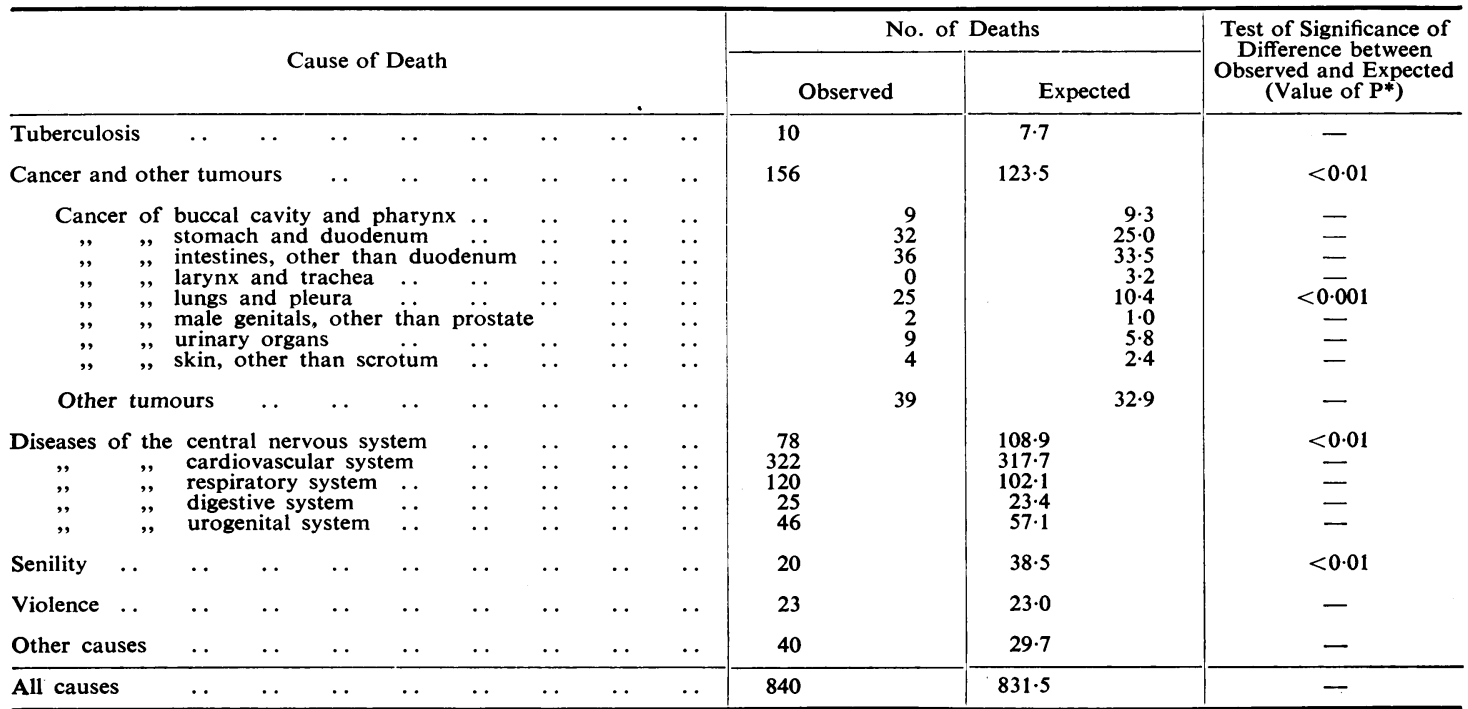

*The values shown for $\mathbf{P}$ are the probabilities with which as great or greater differences between the observed and expected deaths might occur by chance. Values greater than 0.05 are not recorded. 
TABLE 3 CAUSES OF DEATH OF PENSIONERS FROM 1939 TO 1948 COMPARED WITH THE EXPERIENCE OF LONDONERS

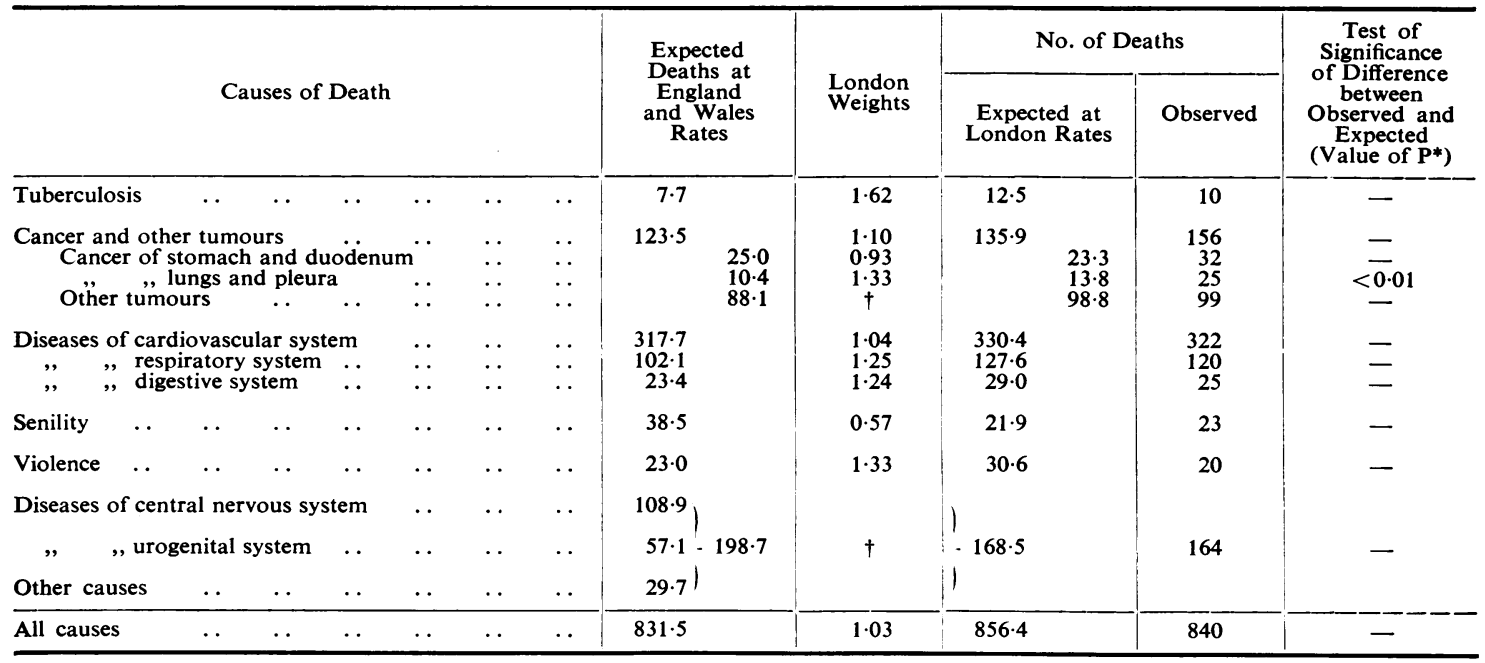

*The values shown for $P$ are the probabilities with which as great or greater differences between the observed and expected deaths might occur by chance. Values greater than 0.05 are not recorded.

†Estimated weights for these groups are 1.13 (other tumours) and 0.87 (diseases of the central nervous system, urogenital system, and other causes); with these weights estimates are obtained of the expected number of London deaths of 99.5 and 172.9 respectively. The figures shown in the Table were obtained by subtracting the number of deaths expected in the other categories from the totals for all cancer and for shown in the Table were obtained by subtracting the nu

be attributed to chance. The close correspondence between the observed and expected deaths for all the categories other than lung cancer suggests that the method of estimating the number of expected deaths is an appropriate one; it enables us to conclude with some confidence that gas-workers suffer a disproportionately heavy mortality from cancer of the lung.

Gas-workers are presumably not all equally exposed to the risk of developing lung cancer. The unsalaried staff of the company were employed in occupations as heterogeneous as those of lamplighter, pipe-fitter, naphthalene washer, and stillman, and the extent of their contact with carcinogenic substances must have been equally varied. The simplest division of the employees is into those working " on the district", i.e. engaged outside the works in laying pipes, fitting stoves, collecting from meters, and those engaged in the works, whether in the production of gas or in the handling of the chemical residues. According to the pension records of all the 840 pensioners who died, 524 $(62.2 \%)$ had been predominantly employed in the works; of the 25 who died of lung cancer 17 $(68.0 \%)$ had been so employed. The difference is statistically quite insignificant. On the other hand, if it is assumed that the proportion of district

$$
\text { * The expected number }=\frac{308}{815} \times 13.8
$$

workers among the "expected" cases of lung cancer would be the same as that among the pensioners who died of other causes, the excess number of deaths observed is not impressive (eight against $5 \cdot 2$ expected*). In contrast, the excess among the works employees is clearly significant (17 against 8.6 expected ; $0.01<\mathrm{P}<0.02$ ).

The occupational history of the lung cancer patients has been investigated in greater detail, but their employment went back to before the first world war and in many cases to the end of the nineteenth century, so that it is unfortunately incomplete. The results are shown in Table 4. One of the district workers was known to have had a period of employment in the works, and the majority of the works employees had been, at one time or another, in close contact with coal-tar or its derivatives. On the evidence available it is not possible to say that the risk is limited to workers concerned in the production of gas and in the treatment of the waste products.

\section{Discussion}

It might be thought that the absence of a fixed age for retirement would have resulted in the inclusion of a disproportionate number of unhealthy men among the pensioners, despite the exclusion from the study of men under 60 , who are the most likely to have been retired for health reasons. 
TABLE 4

OCCUPATIONAL HISTORY OF PENSIONERS DYING OF LUNG CANCER

\begin{tabular}{|c|c|c|c|c|c|c|}
\hline \multirow{2}{*}{\multicolumn{2}{|c|}{$\begin{array}{l}\text { Predominant } \\
\text { Employment } \\
\text { According } \\
\text { to Pension } \\
\text { Records }\end{array}$}} & \multirow[b]{2}{*}{ Case } & \multicolumn{3}{|c|}{ Age at } & \multirow[b]{2}{*}{ Occupational History* } \\
\hline & & & $\begin{array}{c}\text { Starting } \\
\text { Employment }\end{array}$ & $\begin{array}{c}\text { Leaving } \\
\text { Company's } \\
\text { Service }\end{array}$ & Death & \\
\hline District & $\ldots$ & 1 & 37 & 48 & 63 & Lamp-lighter \\
\hline , & 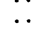 & 2 & 29 & 63 & 78 & Service layer's labourer $\dagger$ \\
\hline ", & .. & 3 & 24 & 63 & 72 & Complaint man till aged 51 , subsequently stove repairer \\
\hline$"$ & . & 4 & 33 & 64 & 70 & Service layer $\dagger$ \\
\hline " & $\cdots$ & 5 & 29 & $\begin{array}{l}63 \\
64\end{array}$ & $\begin{array}{l}74 \\
64\end{array}$ & Lamp attendant \\
\hline$"$ & $\cdots$ & $\begin{array}{l}6 \\
7\end{array}$ & $\begin{array}{l}17 \\
25\end{array}$ & $\begin{array}{l}64 \\
65\end{array}$ & $\begin{array}{l}64 \\
68\end{array}$ & $\begin{array}{l}\text { Gas fitter } \\
\text { Store keeper (dealing with defective meters) }\end{array}$ \\
\hline$\ddot{\prime \prime}$ & $\begin{array}{l}\cdots \\
.\end{array}$ & 8 & 24 & 65 & 74 & Valveman in works till aged 36 , subsequently slot collector \\
\hline Works & 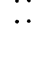 & 9 & 26 & 60 & 75 & $\begin{array}{l}\text { Naphthalene washer attendant aged } 45-46 ; \text { stoking machine } \\
\text { attendant aged } 49 ; \text { lobbyman aged } 54-60 \text { and, for the rest, } \\
\text { a works labourer }\end{array}$ \\
\hline " & . & 10 & 25 & 61 & 75 & Retort house worker and foreman till aged 59, then a yard foreman \\
\hline$"$ & $\cdots$ & 11 & $\begin{array}{l}25 \\
18\end{array}$ & $\begin{array}{l}62 \\
65\end{array}$ & $\begin{array}{l}69 \\
71\end{array}$ & Retort house worker and foreman \\
\hline 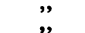 & $\ddot{\cdots}$ & 13 & 36 & 65 & 74 & $\begin{array}{l}\text { Retort house worker and chief carbonizing foreman } \\
\text { Watchman }\end{array}$ \\
\hline$"$ & $\ddot{0}$ & 14 & 35 & 65 & 67 & Stoker, oiler, and doorfitter \\
\hline ", & .. & 15 & 36 & 65 & 68 & Pipefitter \\
\hline ", & . & 16 & 25 & 65 & 68 & Stoking machine driver \\
\hline ", & $\cdots$ & 17 & 39 & 65 & 69 & Stoker, oiler, and doorfitter \\
\hline ", & $\cdots$ & 18 & $\begin{array}{l}24 \\
48\end{array}$ & $\begin{array}{l}64 \\
66\end{array}$ & $\begin{array}{l}77 \\
82\end{array}$ & Labourer, lobbyman, and loader \\
\hline 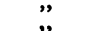 & $\ddot{\ldots}$ & 20 & $\begin{array}{l}48 \\
19\end{array}$ & $\begin{array}{l}66 \\
61\end{array}$ & $\begin{array}{l}82 \\
63\end{array}$ & $\begin{array}{l}\text { Labourer } \\
\text { Stoking machine driver till aged } 38 \text {, then coal trucker and trimmer }\end{array}$ \\
\hline$"$ & $\cdots$ & 21 & 31 & 65 & 71 & Naphthalene plant centrifuger, weighman and storekeeper \\
\hline ", & . & 22 & 28 & 65 & 68 & $\begin{array}{l}\text { Stillman till aged } 48 \text {, then traffic foreman till aged } 56 \text {, then truck } \\
\text { man and slot collector }\end{array}$ \\
\hline " & . & 23 & 29 & 66 & 66 & Hydraulic fitter \\
\hline$"$ & $\cdots$ & 24 & $\begin{array}{l}29 \\
31\end{array}$ & $\begin{array}{l}67 \\
63\end{array}$ & $\begin{array}{l}67 \\
65\end{array}$ & Scurfer (i.e., hot retort cleaner) \\
\hline ," & $\cdots$ & & 31 & & & \\
\hline
\end{tabular}

* Occupations known to result in exposure to tar products shown in italics. The histories are almost certainly incomplete.

†Occupations possibly resulting in exposure to tar products.

Had all, or many, of the disease groups shown an excess mortality it would not have been possible to draw any conclusions from the results, which might well have been due to the pensioners including a disproportionate number of men retired on health grounds. As it is, the close agreement between the observed and expected numbers of deaths from all causes other than from lung cancer justifies the comparison, and it is not reasonable to assume that the excess mortality observed from one cause alone can have been due to differential retirement for health reasons.

In the group studied the mortality from cancer of the lung was $181 \%$ of the mortality, which, it was estimated, would have been suffered by a comparable group of representative Londoners, and $240 \%$ of the mortality calculated for a comparable group representative of all England and Wales. These figures agree well with those obtained by Kennaway and Kennaway (1947) for gas-workers compared with the total adult male population.

A rather greater difference has been obtained by mass radiography (Ministry of Health, 1950). The figures given are, however, crude; they do not take into account the age and sex constitution of the different occupational groups and they refer to all intrathoracic malignant neoplasms. Also the number of cases (four) observed among gasworkers is very small.
It may, therefore, reasonably be concluded that gas-workers suffer a moderately increased risk of developing lung cancer. Whether the risk is solely associated with the production of gas, when carcinogenic hydrocarbons are known to be produced, cannot be determined from the evidence so far provided. The similarity in the proportions of "district" workers among the men who died of lung cancer and among those who died of other causes $(32.0 \%$ and $37.8 \%)$ would suggest that these men are also exposed to an increased risk. An appreciable number of cases must, however, be expected to occur among gas-workers due to causes common to the whole population, e.g., tobacco smoking, and the cases occurring among "district" workers in this investigation are too few to be proof of the existence of any specific occupational factor. It may also be that fuller knowledge of the occupational history of the

CANCER OF THE LUNG

\begin{tabular}{|c|c|c|}
\hline Occupation & $\begin{array}{c}\text { No. of } \\
\text { Deaths } \\
\text { Recorded }\end{array}$ & $\begin{array}{c}\text { Standardized } \\
\text { Mortality } \\
\text { Ratio }\end{array}$ \\
\hline 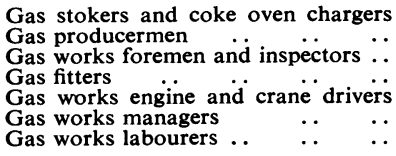 & $\begin{array}{r}85 \\
12 \\
25 \\
41 \\
6 \\
4 \\
96\end{array}$ & $\begin{array}{l}284 \\
202 \\
174 \\
167 \\
138 \\
136 \\
129\end{array}$ \\
\hline
\end{tabular}


district workers would indicate that a disproportionate number of those developing lung cancer had been employed at some previous period in the works. The evidence indicates a specific occupational risk of lung cancer for men engaged in the production of gas, but leaves open the question of there being a specific risk for men employed in gas distribution.

\section{Summary}

The causes of death among a group of pensioned workers of a large London gas company have been compared with those occurring generally among men in London.

Among the pensioners, there were 840 deaths against 856 which could have been expected. Individual causes of death (or groups of causes) showed no appreciable difference from the expected numbers with the exception of lung cancer; 25 deaths were attributed to lung cancer against 13.8 expected.

The excess mortality from lung cancer occurred principally among employees engaged on the production of gas and on the treatment of waste products. (17 observed deaths to 8.6 expected). The deaths occurring among the workers concerned with gas distribution (eight observed to 5.2 expected) were too few to determine whether they were also exposed to any specific risk, or, if they were, whether the risk was different from that suffered by the works employees.

I am most grateful to Professor A. Bradford Hill, Sir Ernest Kennaway, and Dr. D. D. Reid for their advice in the preparation of this paper, and to Miss E. M. Hines and Miss A. H. Huntley for assistance in making the calculations.

\section{REFERENCES}

Henry, S. A., Kennaway, N. M., and Kennaway, E. L. (1931). J. Hyg., Camb., 31, 125.

Kennaway, E. L., and Kennaway, N. M. (1947). Brit. J. Cancer, Ministry of Health (1950). In Report of Chief Medical Officer for
1948. Cmd. 7910. H.M. Stationery Office, London. 